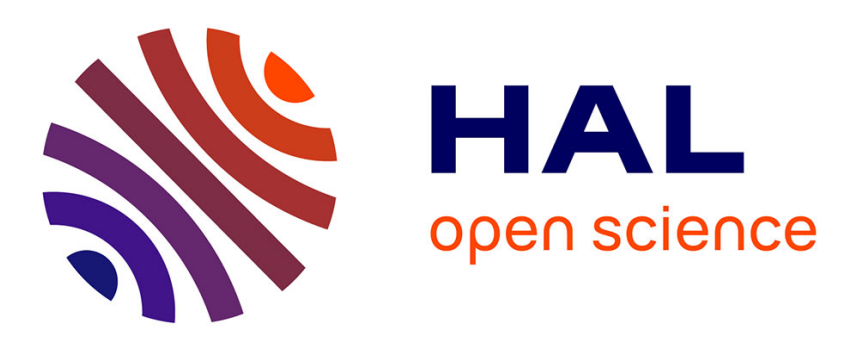

\title{
Real time scatterometry for profile control during resist trimming process
}

\author{
M. El Kodadi, S. Soulan, M. Besacier, P. Schiavone
}

\section{To cite this version:}

M. El Kodadi, S. Soulan, M. Besacier, P. Schiavone. Real time scatterometry for profile control during resist trimming process. Journal of Vacuum Science \& Technology B Microelectronics and Nanometer Structures, 2009, 27 (6), pp.3232-3237. 10.1116/1.3256594 . hal-00462227

\section{HAL Id: hal-00462227 https://hal.science/hal-00462227}

Submitted on 12 Jan 2021

HAL is a multi-disciplinary open access archive for the deposit and dissemination of scientific research documents, whether they are published or not. The documents may come from teaching and research institutions in France or abroad, or from public or private research centers.
L'archive ouverte pluridisciplinaire HAL, est destinée au dépôt et à la diffusion de documents scientifiques de niveau recherche, publiés ou non, émanant des établissements d'enseignement et de recherche français ou étrangers, des laboratoires publics ou privés. 


\title{
Real time scatterometry for profile control during resist trimming process
}

\author{
M. El Kodadia) \\ Laboratoire des Technologies de la Microélectronique, CNRS, 17 rue des Martyrs, 38054 Grenoble, France
}

S. Soulan

Laboratoire des Technologies de la Microélectronique, CNRS, 17 rue des Martyrs, 38054 Grenoble, France and UMI 2958 Georgia Tech-CNRS, Georgia Institute of Technology, 777 Atlantic Dr., Atlanta, Georgia 30332

M. Besacier

Laboratoire des Technologies de la Microélectronique, CNRS, 17 rue des Martyrs, 38054 Grenoble, France

P. Schiavone

UMI 2958 Georgia Tech-CNRS, Georgia Institute of Technology, 777 Atlantic Dr., Atlanta, Georgia 30332

and Laboratoire des Technologies de la Microélectronique, CNRS, 17 rue des Martyres, 38054

Grenoble, France

(Received 7 July 2009; accepted 5 October 2009; published 14 December 2009)

\begin{abstract}
In situ and real time control of the different process steps in semiconductor device manufacturing becomes a critical challenge, especially for the lithography and plasma etching processes. Dynamic scatterometry is among the few solutions able to meet the requirement for in line monitoring. In this article, the authors demonstrate that dynamic scatterometry can be used as a real time monitoring technique during the resist trimming process. Different process parameters, such as chemistries and bias power, were used in the experiments for the demonstration; they discuss the influence of these different parameters on the measurement. For validation purposes, the dynamic scatterometry measurements are compared to three dimensional atomic force microscopy measurements made in the same process conditions. The agreement between both is excellent. (C) 2009 American Vacuum Society. [DOI: 10.1116/1.3256594]
\end{abstract}

\section{INTRODUCTION}

During the micro- and nanofabrication processes, more particularly lithography or plasma etching, the critical dimension $(\mathrm{CD})$ metrology is a key point to reach the required performance of the fabricated devices. In line process control requires real time, nondestructive, and noninvasive monitoring techniques. The conventional $\mathrm{CD}$ metrology techniques, such as atomic force microscopy (AFM) and the CD scanning electron microscopy, are not suited for real time and run to run monitoring because they are either time consuming or destructive and almost impossible to be used in situ.

Optical measurements ${ }^{1}$ are among the few solutions able to meet the requirements for in line monitoring because they are nondestructive and potentially fast. Scatterometry belongs to the family of the optical methods. It uses the analysis of the signature of the light scattered by a periodic structure to infer the shape of a feature. Numerous author's worked to develop the static scatterometry by using different experimental setups. Raymond $e t$ al. $^{2}$ developed the scatterometry using a single wavelength, variable angle readings. The drawback of this type of metrology is the mechanical complexity of the detection scheme. Other setups use Fourier lenses to overcome this major limitation by replacing the mechanical sweep with an all optical scheme. ${ }^{3}$

In contrast to this technique, other authors used specular spectroscopic ellipsometry ${ }^{4-8}$ and reflectometry ${ }^{9}$ using mul-

a)Electronic mail: mohamed.el-kodadi@cea.fr tiple wavelengths and fixed angle. Specular spectroscopic scatterometry can make use of the existing spectroscopic ellipsometers or reflectometers and can be easily installed in situ. In our laboratory, we developed specific software and hardware tools to perform in situ real time scatterometry. Although those are valid whatever the optical instrument is, we have focused up to now on using spectroscopic ellipsometery. ${ }^{10,11}$

The in situ real time control of different steps in semiconductor manufacturing is a very important challenge. The resist trimming ${ }^{12,13}$ process is an example of a manufacturing step that requires a particularly tight control. This step induces a controlled lateral erosion of the photoresist mask aimed at reaching the resolution required by the most advanced technology nodes. However, if resist trimming can help decreasing the resist dimension, it cannot improve the pattern density beyond the capabilities of the lithography. The reduction in resist linewidth is also accompanied by a corresponding increase in the space between lines, thereby preserving the original pitch defined by lithography. For this reason, the process cannot be used to obtain more densely packed dynamic random access memory. However, the reduction in the polysilicon gate length through resist trimming enables the fabrication of faster complementary metal oxide semiconductor logic circuits when advanced lithography reaches its limits.

In this article, we show that the scatterometry can be used for real time monitoring during the resist trimming process of a $248 \mathrm{~nm}$ photoresist for two different etch chemistries; 
TABLE I. Experimental plasma conditions.

\begin{tabular}{llllll}
\hline \hline $\begin{array}{l}\text { Plasma } \\
\text { name }\end{array}$ & Gases & $\begin{array}{l}\text { Bias } \\
\text { power } \\
(\mathrm{W})\end{array}$ & $\begin{array}{l}\text { Vertical etch } \\
\text { rate } \\
(\mathrm{nm} / \mathrm{min})\end{array}$ & $\begin{array}{l}\text { Lateral etch } \\
\text { rate } \\
(\mathrm{nm} / \mathrm{min})\end{array}$ & $\begin{array}{l}\text { Faceting } \\
\text { profile }\end{array}$ \\
\hline $\begin{array}{l}\mathrm{HBr} \text { without } \\
\text { bias }\end{array}$ & $\begin{array}{l}\mathrm{HBr} / \mathrm{O}_{2}(70: 30 \\
\mathrm{SCCM})\end{array}$ & 0 & 90 & 74 & No \\
Ar & $\begin{array}{l}\mathrm{Ar} / \mathrm{O}_{2}(70: 30 \\
\mathrm{SCCM})\end{array}$ & 0 & 210 & 160 & No \\
$\begin{array}{l}\mathrm{HBr} \text { with } \\
\text { bias }\end{array}$ & \begin{tabular}{l}
$\mathrm{HCCM} / \mathrm{O}_{2}(70: 30$ \\
\hline
\end{tabular} & 50 & 210 & 73 & Yes \\
\hline
\end{tabular}

Hbr and Ar. We discuss the influence of chemistries and bias power on the etched profile. Finally, we prove that dynamic scatterometry provides reliable and repeatable results and shows a great potential as a real time monitoring technique for etch process control.

\section{EXPERIMENT}

\section{A. Experimental procedure}

The purpose of this study is to show the ability of the real time scatterometry to control the pattern shape evolution during the resist trimming process. The effect of the main plasma parameters such as bias power and trim chemistries are discussed. Three plasma conditions used to trim the resist in this study are presented in Table I. Two different gas mixtures were investigated $\left(\mathrm{HBr} / \mathrm{O}_{2}\right.$ and $\left.\mathrm{Ar} / \mathrm{O}_{2}\right)$. For the latter, we also used two different substrate polarizations in order to check for the sensitivity of our method to etch rate as well as faceting of the profile. In all the experiments, the source power is fixed at $500 \mathrm{~W}$ and the pressure is fixed at 4 mTorr.

For validation purposes, the approximately $80 \mathrm{~s}$ process has been divided into four different time intervals (20, 40, 60 , and $80 \mathrm{~s}$ ). For each process condition, we took four strictly identical wafers. The three first wafers were trimmed at different times $(20,40$, and $60 \mathrm{~s})$. The fourth wafer is trimmed until the end of the process. Before the process three-dimensional (3D) AFM was used to measure the initial pattern shape. On the test wafers, the initial feature profiles were found to be identical to a few nanometers. We used the real time scatterometry to measure the trimmed feature profile during the etch step. After each experiment, the scatterometry measurements were compared to the 3D AFM.

\section{B. Experimental setup}

Experiments are carried out in an inductively coupled industrial plasma source [decoupled plasma source (DPS) from Applied Materials, Inc.], accepting $200 \mathrm{~mm}$ diameter wafers. The experimental setup has been described in detail elsewhere. ${ }^{14,15}$ The DPS is a high density plasma source where both the source antenna and the bottom electrode are powered. The source consists of a ceramic dome with a rf three-dimensional coil configuration around it. The bottom electrode is powered at a slightly higher frequency than the source (13.56 and $12.56 \mathrm{MHz}$ ), respectively. The source power controls the ion density, while the bottom power (or bias power) controls the energy of ions impinging onto the wafer surface.

The material investigated in this study is a commercial $248 \mathrm{~nm}$ photoresist M78Y resist from JSR deposited on top of a $1.5 \mathrm{~nm}$ layer of silicon dioxide grown on a silicon substrate. It was exposed to a $248 \mathrm{~nm}$ wavelength using an ASML/300 exposure tool. The test pattern is a grating of equal line and space $250 / 250 \mathrm{~nm}$. The test structure area is $10 \times 10 \mathrm{~mm}^{2}$. The resist pattern is exposed to different plasma treatments using either $\mathrm{HBr} / \mathrm{O}_{2}$ or $\mathrm{Ar} / \mathrm{O}_{2}$ chemistries.

We used an in situ spectroscopic phase-modulated multiwavelength ellipsometer UVISEL MWL-16 from Horiba Jobin Yvon (France) to characterize the patterned feature. The ellipsometer is plugged onto the DPS process chamber (Fig. 1). The high acquisition rate of the ellipsometer allows sampling 16 different wavelengths with a $0.5 \mathrm{~s}$ time resolution. That makes it fully compatible for in situ and real time control of resist trimming process, which typically last several tens of seconds. Ellipsometry is based on the measurement of the light polarization change upon reflection from a sample surface or interface. The experimental data are usually expressed as two parameters, ${ }^{16,10} I_{s}$ and $I_{c}$, which are a combination of the ellipsometric angles $\Psi$ and $\Delta$. Such a combination depends on the ellipsometer configuration. These parameters are measured for 16 different wavelengths ranging from 193 to $813 \mathrm{~nm}$. The incident angle is constant at $72.32^{\circ}$. The beam has an elliptical shape, $2 \times 6 \mathrm{~mm}^{2}$ in

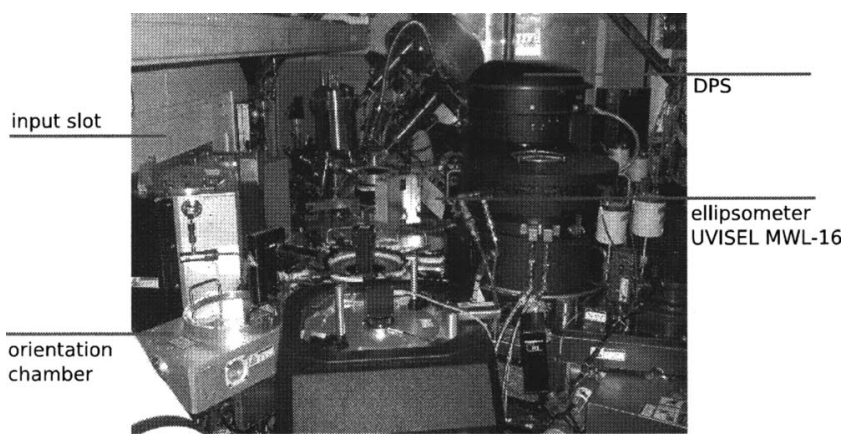

FIG. 1. Overview of the platform DPS CENTURA 5200 from Applied Materials with in situ spectroscopic phase-modulated multiwavelength ellipsometer UVISEL MWL-16 from Horiba Jobin Yvon. 


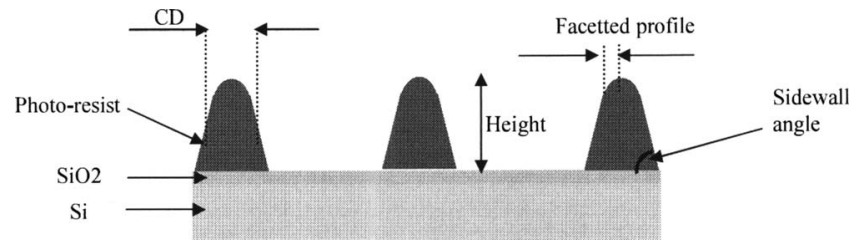

FIG. 2. Schematic of the multilayer grating used as a model for the library generation.

size. It is much smaller than the test structure, which has an area of $10 \times 10 \mathrm{~mm}^{2}$. The measurements are performed in real time in the etch chamber during the process.

\section{AFM}

The trimmed feature profiles have been measured using a 3D-CD AFM ${ }^{17-19}$ from Veeco Instrument. This particular atomic force microscope is designed to provide a 3D image of the surface. It uses specific flared tip, enabling to measure accurately vertical lines (CD and height), as well as the sidewall roughness of the features. The tip used in this study is a flared tip (CDR 120 from Team NanoTec Gmbh) with a diameter of $120 \mathrm{~nm}$, an edge radius of about $20 \mathrm{~nm}$, and an effective tip length of $580 \mathrm{~nm}$. It is used to determine the pattern profile. For each data point, we performed six slightly shifted line scans in order to get an averaged measurement of the resulting profile, therefore reducing the measurement error. This has also the advantage of making the 3D AFM measurement less local in space and more prone to be compared to scatterometry which provides a measurement that is averaged over the size of the light spot. Before and after each measurement, a tip qualification is carried out to ensure the validity of the measurement. The dynamic repeatability of the $3 \mathrm{D}$ AFM measurement is estimated to $1 \mathrm{~nm} .^{20}$

\section{Scatterometry}

Scatterometry is an optical measurement technique based on the analysis of the light scattered from a periodic array of features. It is a typical inverse problem approach that extracts a measurement by comparing the signature acquired by an optical metrology instrument (in our case a spectroscopic ellipsometer) to a set of computed signatures. The so-called direct problem consist of determining the diffraction efficiencies of the given diffraction grating using a rigorous electromagnetic solver based on the modal method by Fourier expansion (MMFE) $)^{21,22}$ also known as rigorous coupled wave analysis (RCWA). The inverse problem consists of determining the shape of the lines of the periodic structure from an experimental signature acquisition. The approach that is most commonly used in the industry to solve this problem is to generate a library of scattering signatures. ${ }^{23}$ This method has a major additional advantage for us: it is real time compliant as the solving time is perfectly predictable.

The library of computed signatures is build up for different combinations of profile parameters (Fig. 2), which are supposed to cover the range of possible profiles expected to be encountered along the experiment. In view of the profiles we had to deal with, we chose a model with four parameters [CD, height, sidewall angle $\left(\theta_{1}\right)$, and profile faceting $\left.\left(\theta_{2}\right)\right]$. This allows representing a variety of shapes, which are basically trapezoids with top rounded corners. The profile faceting is presented here by parabolic top corners described by the following equation:

$$
f(x)=\frac{1}{2} \tan \left(\pi / 2-\theta_{2}\right)\left(y-y_{0}\right)^{2} .
$$

Our experience showed that the onset of the corner rounding can, without a lack of generality, be set to a value $y_{0}$ equal to $85 \%$ of the feature height.

Material optical properties $n$ (reflective index) and $k$ (extinction coefficient) of each layer are known parameters of the problem as well as the thickness of the oxide layer.

When the raw signatures are measured, the best match to these data is searched in the previously computed library. Although the library building is time consuming and requires high performance processors, solving the inverse problem can be fast because pattern matching is reduced here to a simple numerical database search. Nevertheless, it is too much time consuming to solve the inverse problem for each time step with a brute force approach. We use graphic processing unit (GPU) to accelerate the database search. A full description of this method can be found elsewhere. ${ }^{10,11}$

The ellipsometer acquisition rate is 2 measurements/s. Our postprocessing using the GPU can be much faster (up to 10 inversions/s). Thus, the current acquisition rate of our setup is limited by the ellipsometer at $2 \mathrm{~Hz}$. This is not an issue since the process duration is in the range of several tens of seconds.

\section{RESULTS AND DISCUSSION}

\section{A. Reproducibility of the results}

Two different approaches can be envisioned to perform the validation of real time scatterometry with 3D AFM measurements. The first one is to use a single wafer that is etched partially, taken out of the chamber, characterized using the 3D AFM, and placed back in the etch tool for the following of the process, potentially interrupted again for other measurements all along the process time. We figured out and experienced that this method was not reliable as interrupting the process would significantly alter the conduct of the etch step. Instead we found much more reproducible results using several wafers of the same batch and stopping the process at different times for each of them as described in Sec. II. As an illustration, Fig. 3 shows the ellipsometric signals for 4 wavelengths out of the 16 available, and the corresponding signatures are drawn. They correspond to four wafers that were etched at 20, 40, 60, and $80 \mathrm{~s}$, respectively. It can be seen that all of them are almost perfectly superimposed. This is a strong evidence that our metrology is fully legitimate. At the same time it gives an idea of the repeatability of the ellipsometric measurement. 

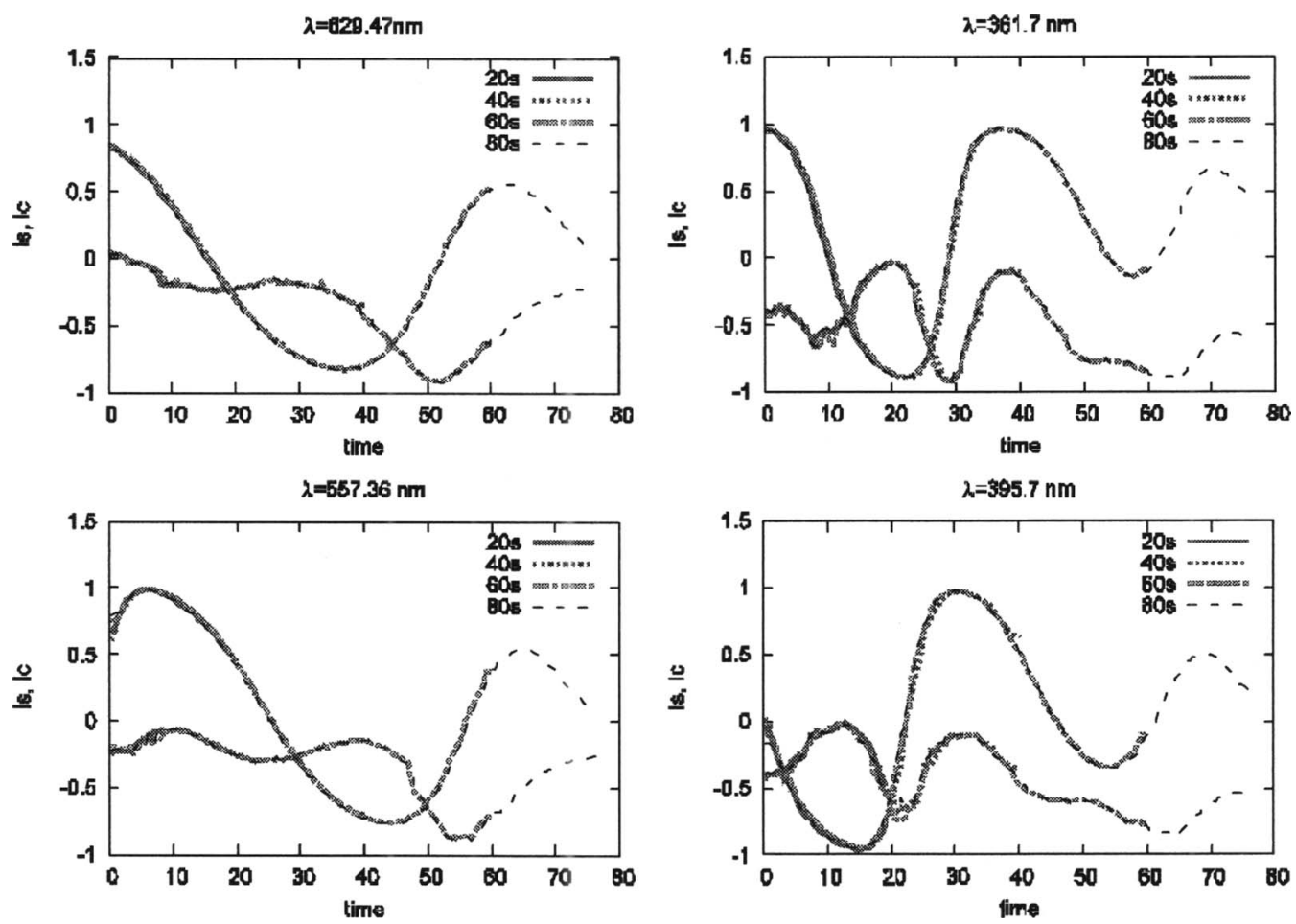

FIG. 3. Real time ellipsometric data for four wavelengths during the etching process.

\section{B. Monitoring of the etch process}

A comparison between dynamic scatterometry profile shape (CD and height) and the $3 \mathrm{D}$ AFM measurements is reported in Figs. 4-6. The reconstructed profiles, extracted using the real time scatterometry at several different time steps $(70,140$, and $120 \mathrm{~s})$, are compared to 3D AFM profiles

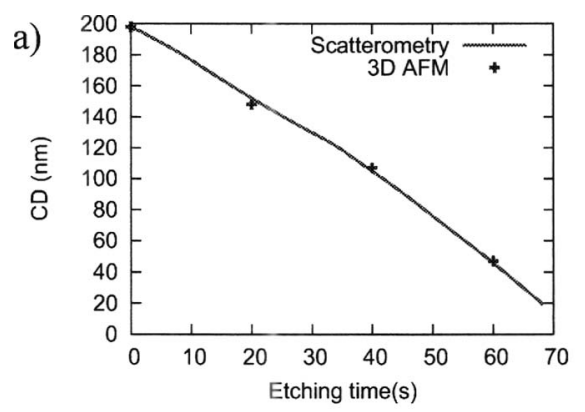

b)

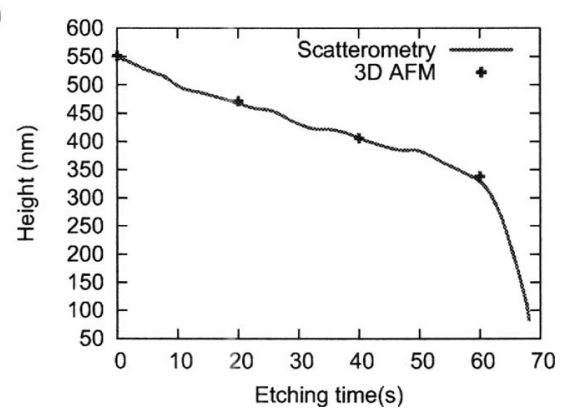

FIG. 4. Real time measurement results (solid line): (a) $\mathrm{CD}$ and (b) height of resist feature vs the processing time in $\mathrm{Ar} / \mathrm{O}_{2}$ plasma. 3D AFM data (cross shape markers) are shown for reference. measured on separate wafers etched during the same time. Overall, the agreement between AFM and scatterometry is very good since the difference in width and height between each other is always less than $3 \%$ for different chemistries and power bias.
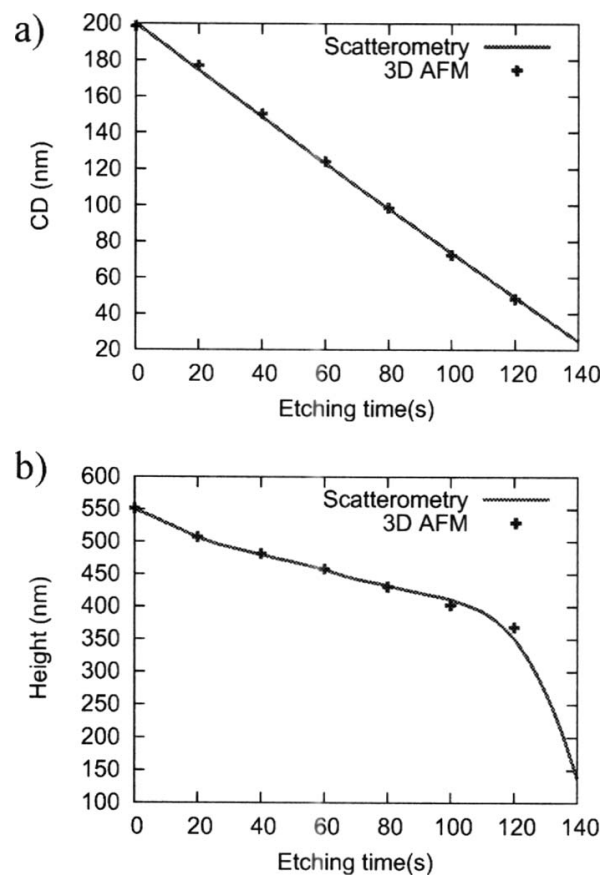

FIG. 5. Real time measurement results (solid line): (a) CD and (b) height of resist feature vs the processing time in $\mathrm{HBr} / \mathrm{O}_{2}$ without bias power. 3D AFM data (cross shape markers) are shown for reference. 

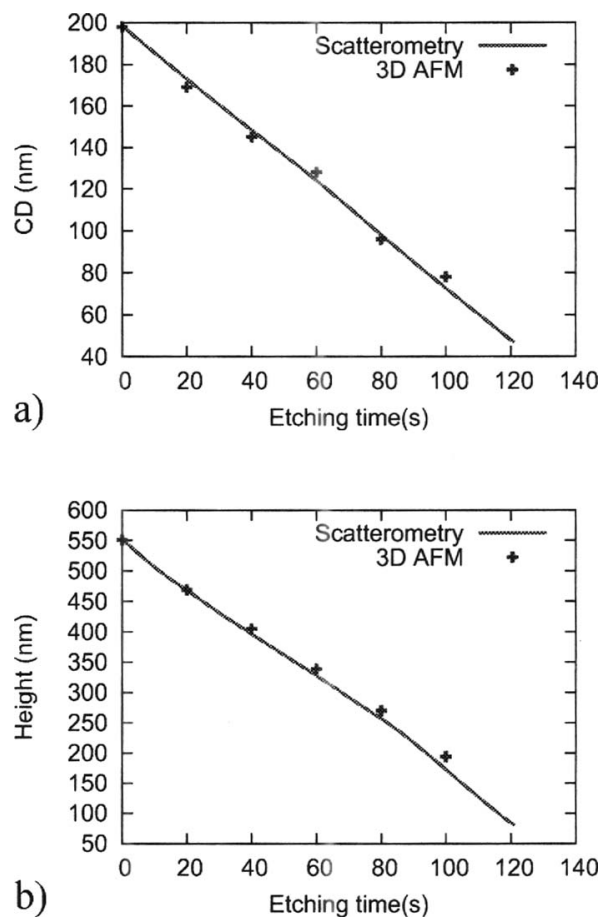

FIG. 6. Real time measurement results (solid line): (a) $\mathrm{CD}$ and (b) height of resist feature vs the processing time in $\mathrm{HBr} / \mathrm{O}_{2}$ with bias power. 3D AFM data (cross shape markers) are shown for reference.

\section{Influence of bias power and chemistries}

For the $\mathrm{HBr}$ process, we used two different bias conditions: 0 and $50 \mathrm{~W}$. The result of the comparison is reported in Figs. 5 and 6. We see that an increase in bias power logically results in an increase in the vertical etch rate from 90 to $210 \mathrm{~nm} / \mathrm{min}$. These results are very consistent with the evolution of the etch rate reported in literature. ${ }^{13}$ Lateral trimming rate is $76 \mathrm{~nm} / \mathrm{min}$ for the two bias conditions. Figures 7 and 8 show the evolution of the resist profile during the process. We first observe the perfect agreement between real time scatterometry (flat color) and cross section of the AFM measurement (surrounding solid line). Then, it can be seen that increasing the power bias favors a faceting of the resist line, which is visible on the scatterometric measurement as well as on the 3D AFM.

The results also allow comparing the two plasma chemistries. When no bias power is applied, the vertical etch rates are 210 and $90 \mathrm{~nm} / \mathrm{min}$ for $\mathrm{Ar} / \mathrm{O}_{2}$ and $\mathrm{HBr} / \mathrm{O}_{2}$, respectively. The lateral etch rates are 160 and $74 \mathrm{~nm} / \mathrm{min}$. The etch rate with $\mathrm{Ar}$ is twice as fast as the $\mathrm{HBr}$ etch rate. This is out of the scope of this article to explain the reason of this difference. We just want to emphasize that scatterometry is a reliable technique that is able to control a fast resist trimming process in real time.

\section{CONCLUSION}

In this article, we used the in situ real time scatterometry metrology to monitor the resist trimming process. We applied and validated this technique to different chemistries and bias power. This study proves that real time scatterometry pro-
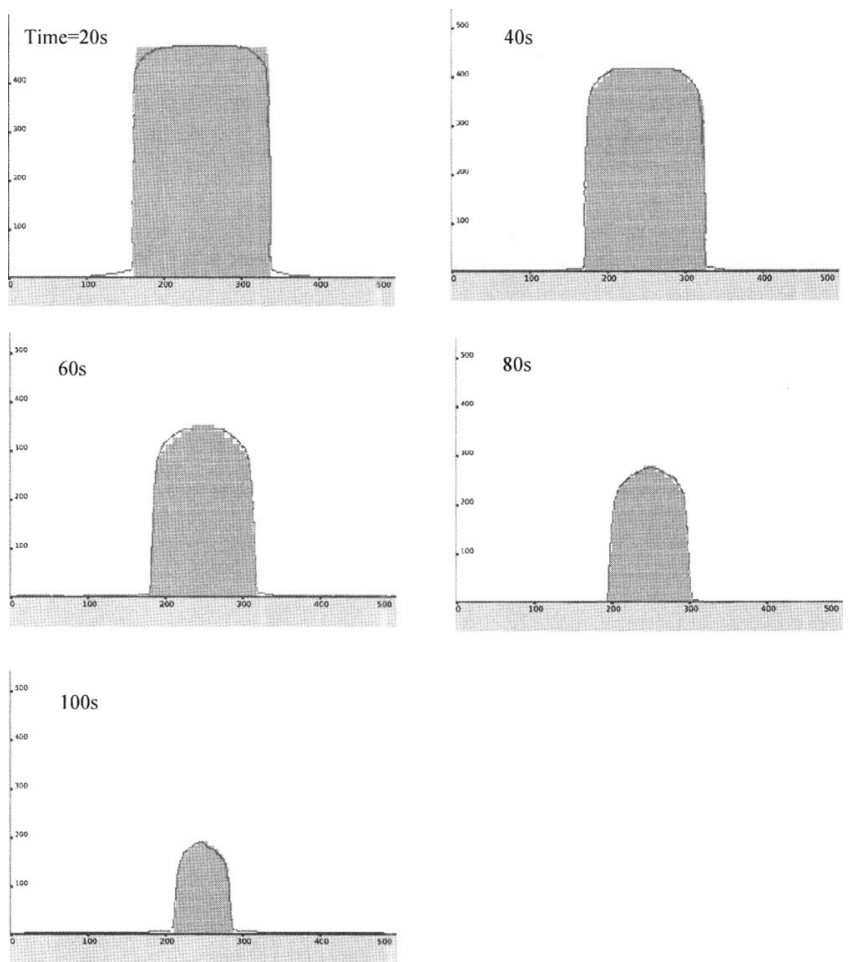

FIG. 7. Comparison between the scatterometry image (flat color) and cross section of the AFM measurement (surrounding solid line) for different processing times (20,40,60, 80, and $100 \mathrm{~s})$. Process conditions: $\mathrm{HBr} / \mathrm{O}_{2}$ with bias.
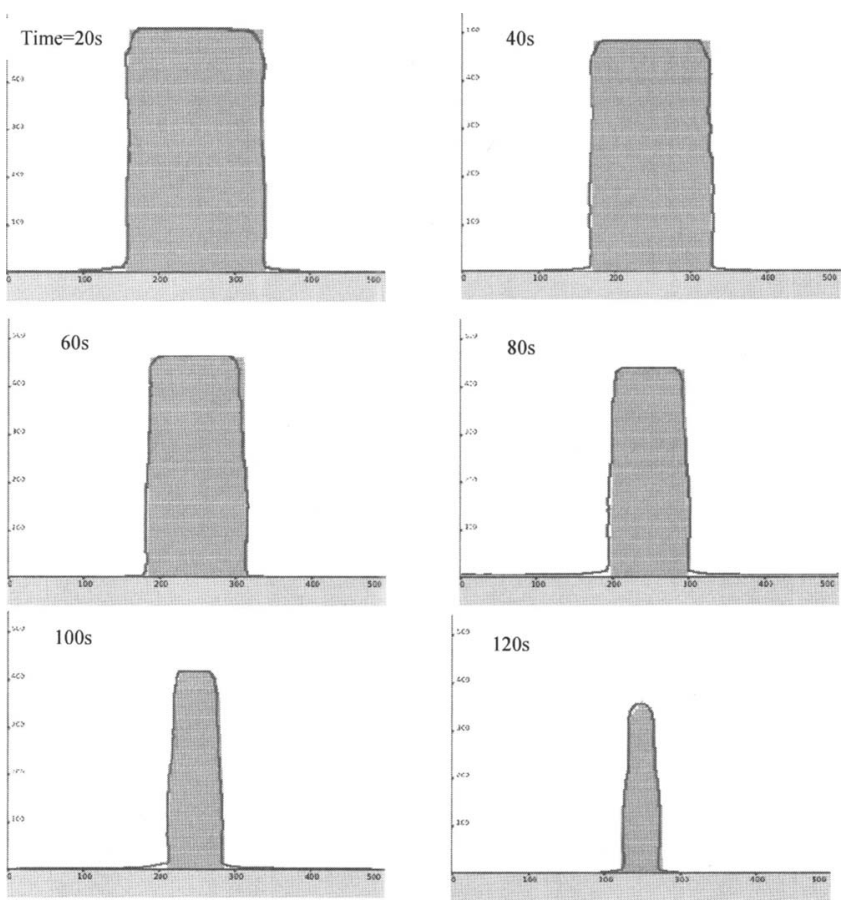

FIG. 8. Comparison between the scatterometry image (flat color) and cross section of the AFM measurement (surrounding solid line) for different processing times (20,40,60,80,100, and $120 \mathrm{~s})$. Process conditions: $\mathrm{HBr} / \mathrm{O}_{2}$ without bias. 
vides reliable results and shows a great potential as a monitoring technique for etch process control. The comparison between scatterometry measurement and 3D AFM measurement shows a good match for a variety of different pattern shape, within a few percent in size. The profile evolution can also be handled. We showed that faceting can be measured with an excellent agreement with our reference metrology. We proved that the scatterometry can reliably extract the pattern shape in two dimensions and in real time. This characterization technique can be viewed as an invaluable tool for the accurate control of the patterning of current and next generation of semiconductor devices.

\section{ACKNOWLEDGMENT}

The authors would like to thank E. Pargon (LTM-CNRS) for a number of useful discussions.

${ }^{1}$ S. S. H. Naqvi, S. H. Zaidi, S. R. J. Brueck, and J. R. McNeil, J. Vac. Sci. Technol. B 12, 3600 (1994).

${ }^{2}$ C. J. Raymond, M. Murnane, S. Prins, S. S. H. Naqvi et al., J. Vac. Sci. Technol. B 15, 361 (1997).

${ }^{3}$ J. Hazart, P. Barritault, S. Garcia, T. Lauroux, P. Boher, and K. Tsujino, Proc. SPIE 6518, 6518A (2007).

${ }^{4}$ H. L. Maynard, N. Layadi, and J. T. C. Lee, Thin Solid Films 313-314, 398 (1998).

${ }^{5}$ X. Nui, N. Jakatdar, J. Boa, C. Spanos, and S. Yedur, Proc. SPIE 3677,
159 (1999).

${ }^{6}$ V. G. Kechagias, M. Gioti, S. Logothetidis, R. Benferhat, and D. Teer, Thin Solid Films 364, 213 (2000).

${ }^{7}$ H. L. Maynard, N. Layadi, and J. T. C. Lee, J. Vac. Sci. Technol. B 15, 109 (1997).

${ }^{8}$ N. Blayo, R. A. Cirelli, F. P. Klemens, and J. T. C. Lee, J. Opt. Soc. Am. 12, 591 (1995)

${ }^{9}$ H. T. Huang and F. L. Terry, Jr., Thin Solid Films 468, 339 (2004).

${ }^{10}$ M. El Kodadi, S. Soulan, M. Besacier, and P. Schiavone, Microelectron. Eng. 86, 1040 (2009).

${ }^{11}$ S. Soulan, M. Besacier, and P. Schiavone, Proc. SPIE 6617, 661713 (2007).

${ }^{12}$ C. Y. Sin and B. H. Chen, J. Vac. Sci. Technol. B 20, 1974 (2002).

${ }^{13}$ E. Pargon and O. Joubert, J. Vac. Sci. Technol. B 22, 1896 (2004).

${ }^{14}$ S. Ma, M. Jain, and J. D. Chinn, J. Vac. Sci. Technol. A 16, 1440 (1998).

${ }^{15}$ G. Cunge, R. L. Inglebert, O. Joubert, L. Vallier, and N. Sadeghi, J. Vac. Sci. Technol. B 20, 2137 (2002).

${ }^{16}$ M. Kildemo, P. Bulkin, S. Deniau, and B. Drévillon, Appl. Phys. Lett. 68, 3395 (1996).

${ }^{17}$ J. Foucher and K. Miller, Proc. SPIE 5375, 444 (2004).

${ }^{18}$ G. Dahlen, M. Osborn, N. Okulan, W. Foreman, A. Chand, and J. Foucher, J. Vac. Sci. Technol. B 23, 2297 (2005).

${ }^{19}$ J. Thiault, J. Foucher, J. H. Tortai, O. Joubert, S. Landis, and S. Pauliac, J. Vac. Sci. Technol. B 23, 3075 (2005).

${ }^{20}$ L. Mininni, J. Foucher, and P. Faurie, Proc. SPIE 6518, 651830 (2007).

${ }^{21}$ M. G. Moharam, E. B. Grann, D. A. Pommet, and T. K. Gaylord, J. Opt. Soc. Am. A 12, 1068 (1995).

${ }^{22}$ Lifeng Li and C. W. Haggans, J. Opt. Soc. Am. A 10, 1184 (1993).

${ }^{23}$ X. Niu, N. Jakatdar, J. Bao, and C. J. Spanos, IEEE Trans. Semicond. Manuf. 14, 97 (2001). 